\title{
DEVELOPMENT AND VALIDATION OF REVERSED-PHASE HIGH-PERFORMANCE LIQUID CHROMATOGRAPHY METHOD FOR GABAPENTIN AND ITS RELATED SUBSTANCES IN CAPSULE DOSAGE FORM AND EXCIPIENT COMPATIBILITY STUDIES
}

\author{
AFROZ PATAN*, ALEKHYA K, VIJEY AANANDHI M \\ Department of Pharmaceutical Chemistry and Analysis, School of Pharmaceutical Sciences, Vels Institute of Sciences, Technology and \\ Advanced Studies, Pallavaram, Chennai - 603 117, Tamil Nadu, India. Email: afroz.sps@velsuniv.ac.in
}

Received: 10 October 2018, Revised and Accepted: 11 December 2018

ABSTRACT

Objective: A simple, accurate, precise, and reversed-phase high-performance liquid chromatography (RP-HPLC) method was developed and validated for gabapentin (GBP) and its related substances in the capsule dosage form and excipient compatibility studies.

Methods: The review of literature indicates that various methods have been reported for the estimation of GBP. When some excipients were used for GBP, it produced degradation product called lactam due to the presence of more water content. Hence, a novel RP-HPLC method has been developed for studying excipient compatibility and related substances of GBP in capsule dosage form using excipients such as lactose anhydrous and dried maize starch which is having less water activity. Waters Alliance e2695 separation module with ultraviolet/photodiode array (UV/PDA) detector with Inertsil C8 $(250 \mathrm{~mm} \times 4.6 \mathrm{~mm}) ; 5 \mu \mathrm{m}$ with an injection volume of $50 \mu \mathrm{l}$ is injected and eluted with the (gradient program) mobile Phase A buffer: acetonitrile (940:60) and mobile phase B buffer: acetonitrile (700:300) pH 6.9 with $5 \mathrm{~N}$ potassium hydroxide which is pumped at a speed of $1.5 \mathrm{ml} / \mathrm{min}$ and detected by UV/PDA detector at $210 \mathrm{~nm}$. The peaks of GBP and GBP-related compound A are well separated at $6.7 \mathrm{~min}$ and $34.5 \mathrm{~min}$, respectively.

Results: The method developed was approved for various parameters such as accuracy, specificity, precision, intermediate precision, range, linearity, robustness, limit of detection, limit of quantification, steadiness, and system suitability according to the International Conference on Harmonization guidelines. The results got were according to the acceptance criteria.

Conclusion: The technique proposed was assured for detection of related substances in the marketed formulation and could be used for the routine analysis of GBP and GBP-related compound A in the capsule dosage form.

Keywords: Gabapentin, Gabapentin-related compound A, Reversed-phase high-performance liquid chromatography, Validation and capsule dosage forms.

(c) 2018 The Authors. Published by Innovare Academic Sciences Pvt Ltd. This is an open access article under the CC BY license (http://creativecommons. org/licenses/by/4. 0/) DOI: http://dx.doi.org/10.22159/ajpcr.2018.v11s4.31707

\section{INTRODUCTION}

Gabapentin (GBP) is chemically 2-[1-(aminomethyl)cyclohexyl]acetic acid as shown in Fig. 1. By expansion of a cyclohexyl group to gammaaminobutyric acid (GABA) GBP was formed, which allowed this form of GABA to cross the blood-brain barrier.

GBP was first incorporated to mimic the chemical structure of the neurotransmitter GABA, but it was not able to act on the similar cerebrum receptors.

GBP stops the formation of new synapses. GBP has been found to decrease calcium flow after constant application by binding to the $\alpha 2 \delta$ subunit ( 1 and 2 ) but not by acute application through an impact on trafficking of voltage-dependent calcium flow in central nervous system. The calcium channel trafficking is another possible mechanism, yet the exact mechanism of action of GBP stays in dispute.

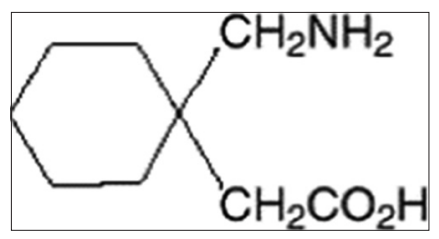

Fig. 1: Structure of gabapentin
GBP obviously has a novel mechanism of action, most likely including potentiation of GABA - mediated inhibition and conceivably inactivation of sodium channels also.

The literature survey [1-21] indicates that when lactose was used as an excipient for GBP, it produced an impurity called lactam, due to which stability was affected. Hence, according to the International Conference on Harmonization (ICH) guidelines, an attempt was made to create and validate a basic simple, accurate, precise, and efficient reversed-phase high-performance liquid chromatography (RP-HPLC) technique for the excipient compatibility studies and related substances of GBP using lactose monohydrate and maize starch as the excipients.

\section{METHODS}

\section{Instrumentation}

High-performance liquid chromatography (waters) with quaternary pump, with Inertsil C8 $(250 \mathrm{~mm} \times 4.6 \mathrm{~mm})$; $5 \mu \mathrm{m}$ column detection of drug carried by ultraviolet (UV) detector data processing was carried out by Empower - 2 Software, weighing balance (Sartorius), sonicator (spectra lab), and pH meter (polmon).

\section{Reagents and chemicals}

GBP working standard, GBP-related compound A, acetonitrile (HPLC grade), HPLC water, potassium dihydrogen orthophosphate, potassium hydroxide; reference standards: GBP - USP certified reference standard 
Bengaluru, GBP-related compound A - USP comprehensive ranking system, and excipients: Lactose monohydrate, lactose anhydrous, maize starch, and dried maize starch, talc were used.

\section{Chromatographic conditions}

Column: Inertsil C8 (250 mm $\times 4.6 \mathrm{~mm}$ ); $5 \mu \mathrm{m}$ or equivalent

Flow rate: $1.5 \mathrm{ml} / \mathrm{min}$

Injection volume: $50 \mu \mathrm{l}$

Column (oven temp): Ambient

Wavelength: UV/PDA at $210 \mathrm{~nm}$

Elutiontype: Gradient.

\section{Gradient program}

Time (min) Mobile Phase A (\%) Mobile Phase B (\%)

$0.0-4.0 \quad 100 \quad 0$

$4.0-45.0 \quad 0 \quad 100$

$45.0-45.1100 \quad 0$

$45.1-50.0100 \quad 0$

The peaks of GBP and GBP-related compound A are well separated at $6.7 \mathrm{~min}$ and $34.5 \mathrm{~min}$, respectively.

\section{Solution preparation}

Preparation of $5 \mathrm{~N}$ potassium hydroxide

Weigh about $28.06 \mathrm{~g}$ of potassium hydroxide transfer into $100 \mathrm{ml}$ glass beaker, pour about $50 \mathrm{ml}$ of purified water and dissolve it and makeup to $100 \mathrm{ml}$ with water.

\section{Diluent}

Dissolve $1.2 \mathrm{~g}$ of dihydrogen potassium orthophosphate $\mathrm{KH}_{2} \mathrm{PO}_{4}$ in $1000 \mathrm{ml}$ of water and maintain the $\mathrm{pH}$ at 6.9 using $5 \mathrm{~N}$ potassium hydroxide.

\section{Preparation of mobile phase $A$}

Dissolve $1.2 \mathrm{~g}$ potassium dihydrogen orthophosphate in $940 \mathrm{ml}$ of water. Adjust the $\mathrm{pH}$ to 6.9 with $5 \mathrm{~N}$ potassium hydroxide and add $60 \mathrm{ml}$ of acetonitrile and mix well. The solution was filtered through a membrane filter $(0.45 \mu \mathrm{m})$ and degassed.

\section{Preparation of mobile phase $B$}

Dissolve $1.2 \mathrm{~g}$ potassium dihydrogen orthophosphate in $700 \mathrm{ml}$ of water. Adjust the $\mathrm{pH}$ to 6.9 using $5 \mathrm{~N}$ potassium hydroxide and add $300 \mathrm{ml}$ of acetonitrile and mixed well. The solution was filtered through a membrane filter $(0.45 \mu \mathrm{m})$ and degassed.

\section{GBP-related compound A stock solution}

Accurately weigh about $10 \mathrm{mg}$ of GBP-related compound A RS in a volumetric flask of $20 \mathrm{ml}$ volume add diluent to solubilize the content and makeup to the volume by using diluent.

\section{Standard preparation}

Accurately weigh $0.025 \mathrm{~g}$ of GBP working standard into a volumetric flask of $50 \mathrm{ml}$, add diluent to solubilize the content by shaking for $1 \mathrm{~min}$ and make to volume with diluent. Pipette out $2 \mathrm{ml}$ of this solution and $2 \mathrm{ml}$ of GBP-related compound A stock solution into $25 \mathrm{ml}$ and makeup to the volume with diluent and mixed well. The solution was filtered through a membrane filter $(0.45 \mu \mathrm{m})$.

\section{Calibration curves}

The range and linearity of the analytical method for GBP was confirmed by injecting the various concentrations of GBP standard preparation prepared according to the range of limit of quantification (LOQ) covering six different concentrations up to $150 \%$ of specification level into the chromatograph, and the response was observed to be linear within that range. The linearity of GBP and each related substance was plotted by a graph between response factor and concentration. The relationship between the concentration and response was linear in the specified range, and the correlation coefficient was 0.99 for GBP and each related substance.

\section{Sample preparation}

Remove and weigh the contents of not fewer than 20 capsules. Transfer an accurate weighed portion of the powder, approximately to about $500 \mathrm{mg}$ of GBP, to $25 \mathrm{ml}$ volumetric flask and add about $15 \mathrm{ml}$ of diluent. Shake for $1 \mathrm{~min}$ and makeup to the level using the diluent and then mix well. The solution was filtered through a membrane filter $(0.45 \mu \mathrm{m})$. Collect the filtrate, after removing the certain amount of the filtrate.

\section{Procedure}

Equilibrate the column for not $<30 \mathrm{~min}$ with an initial gradient and rate of flow was kept at $1.5 \mathrm{~mL} / \mathrm{min}$. Inject separately $50 \mu \mathrm{L}$ of the above all solutions into the HPLC and measure the peak responses for the major peaks record the chromatograms. The typical chromatogram is shown in Figure 2.

\section{RESULTS AND DISCUSSION}

\section{Method validation procedure}

The objective of the method validation as stated in ICH guidelines is to exhibit that the technique is reasonable for its intended purpose.

\section{Accuracy (recovery studies)}

By adding known quantity of known impurity, the recovery studies were performed standards to test solution in the range of LOQ to $150 \%$ of specification limit specified in the method of analysis, with four different concentrations (LOQ $50 \%, 100 \%$, and $150 \%$ in triplicate) to represent the entire range. The percentage recovery and relative standard deviation (RSD) for all the values of percentage recovery were reported. The mean percentage recovery of all known related substance

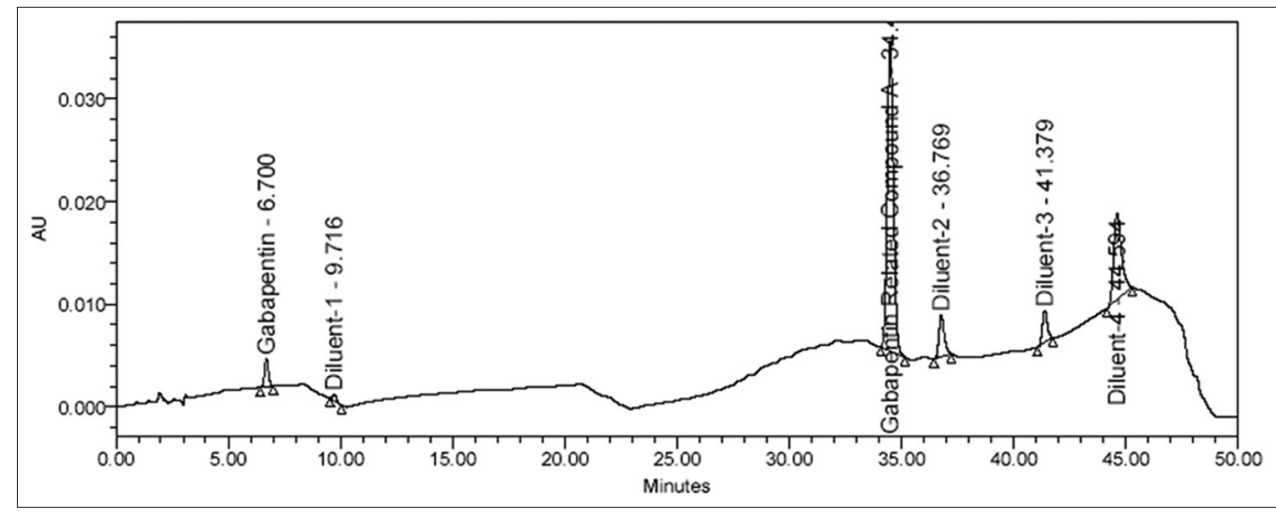

Fig. 2: Typical graph of gabapentin 
Table 1: Recovery of GBP-related compound A

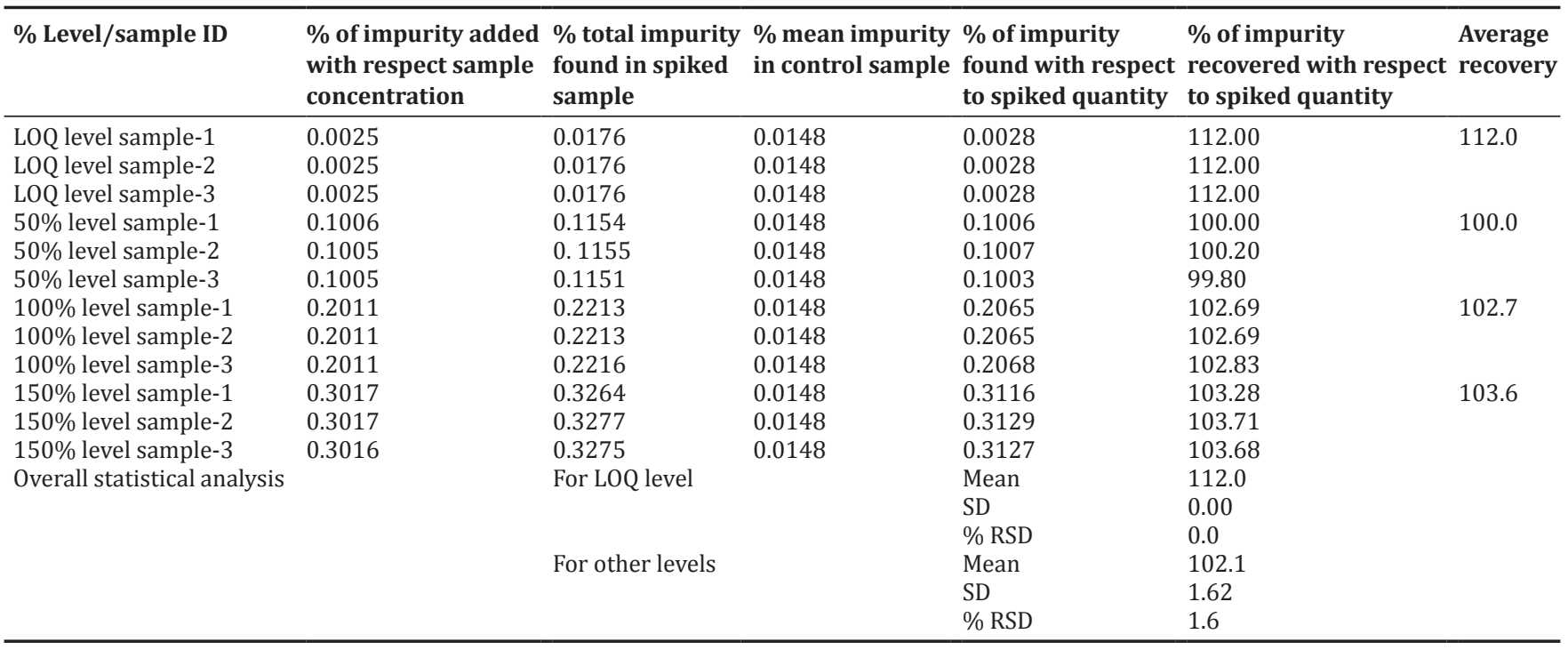

GBP: Gabapentin, SD: Standard deviation, LOQ: Limit of quantification, RSD: Relative standard deviation

Table 2: Percentage of GBP-related compound A at RT 34.4 for six samples of the same batch

\begin{tabular}{llll}
\hline Sample ID & $\begin{array}{l}\text { Weight of sample } \\
\text { taken (mg) }\end{array}$ & $\begin{array}{l}\text { GBP-related compound A at } \\
\text { RT } \sim \mathbf{3 4 . 4}\end{array}$ & $\begin{array}{l}\text { \% of GBP-related compound A at RT 34.4 with respect to GBP-related } \\
\text { compound A (standard solution) }\end{array}$ \\
\hline Sample-1 & 662.52 & 41,642 & 0.01 \\
Sample-2 & 661.30 & 44,841 & 0.01 \\
Sample-3 & 661.83 & 45,046 & 0.01 \\
Sample-4 & 662.92 & 44,172 & 0.01 \\
Sample-5 & 661.62 & 43,863 & 0.01 \\
Sample-6 & 662.04 & 43,504 & 0.01 \\
Mean & & & 0.01 \\
SD & & & 0.00 \\
\% RSD & & & 0.0 \\
\hline
\end{tabular}

GBP: Gabapentin, SD: Standard deviation, RSD: Relative standard deviation

Table 3: Percentage of total impurities for six samples of the same batch

\begin{tabular}{ll}
\hline Sample ID & Total impurities (\%) \\
\hline Sample-1 & 0.01 \\
Sample-2 & 0.01 \\
Sample-3 & 0.01 \\
Sample-4 & 0.01 \\
Sample-5 & 0.01 \\
Sample-6 & 0.01 \\
Mean & 0.01 \\
SD & 0.00 \\
\% RSD & 0.0 \\
\hline
\end{tabular}

SD: Standard deviation, RSD: Relative standard deviation

GBP-related compound A of nine determinations over three different concentrations and three determinations at LOQ levels were within the acceptance limit is shown in Table 1.

\section{Precision}

Repeatability of analytical technique was established by assessing the related substances for six different test solutions of the same batch. The percentage of related substances for all six test solutions was calculated, and the percentage (RSD) for the same was reported. The evaluation of related substances, i.e., GBP-related Compound A, for all six determinations has been presented in Tables 2 and 3. Unknown impurity is not detected in the all six sample preparations of the sample batch.

\section{Ruggedness}

The ruggedness of the analytical method was confirmed by estimating the related substances for six different test solutions of the same batch by another analyst on a different HPLC system using another column on some another day. The percentage of related substances for all six test solutions was calculated, and the percentage RSD was reported for the same. The analytical method intermediate precision was established by estimating the related substances for six different samples of the same batch by another analyst on a different HPLC system using a column of another lot number on some another day. The evaluation of related substances, i.e., GBP-related Compound A, for all six determinations has been presented in Tables 4 and 5. Two unique analysts carried out the analysis of the same batch of GBP 400 mg capsules on two distinct instruments, with two different columns on distinct days. The details presented in Table 6.

\section{Linearity}

The linearity of the analytical method was demonstrated by injecting the various concentrations of all known impurities, and GBP prepared according to the range of LOQ covering at least six different concentration levels up to $150 \%$ of specification level into the chromatograph. Regression analysis results of the linearity data have been presented in Table 7 and Figure-3. The linearity and range of the analytical method for GBP-related Compound A was established by injecting the various concentrations of GBP-related Compound A standard preparation prepared according to a range of LOQ covering six different concentrations up to $150 \%$ of specification level into the chromatograph. Regression analysis results of the linearity and range of the analytical method for GBP-related Compound A have been presented in Table 8 and linearity graph of GBPrelated Compound A, presented in Figure-4. 


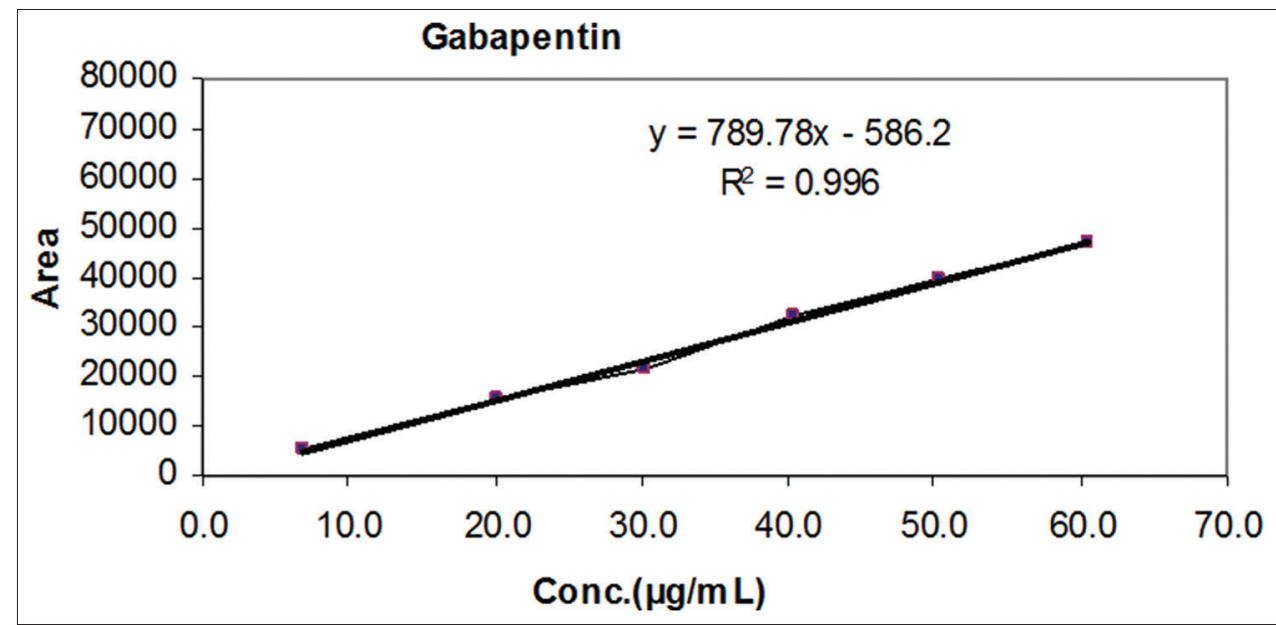

Fig. 3: Linearity graph of gabapentin

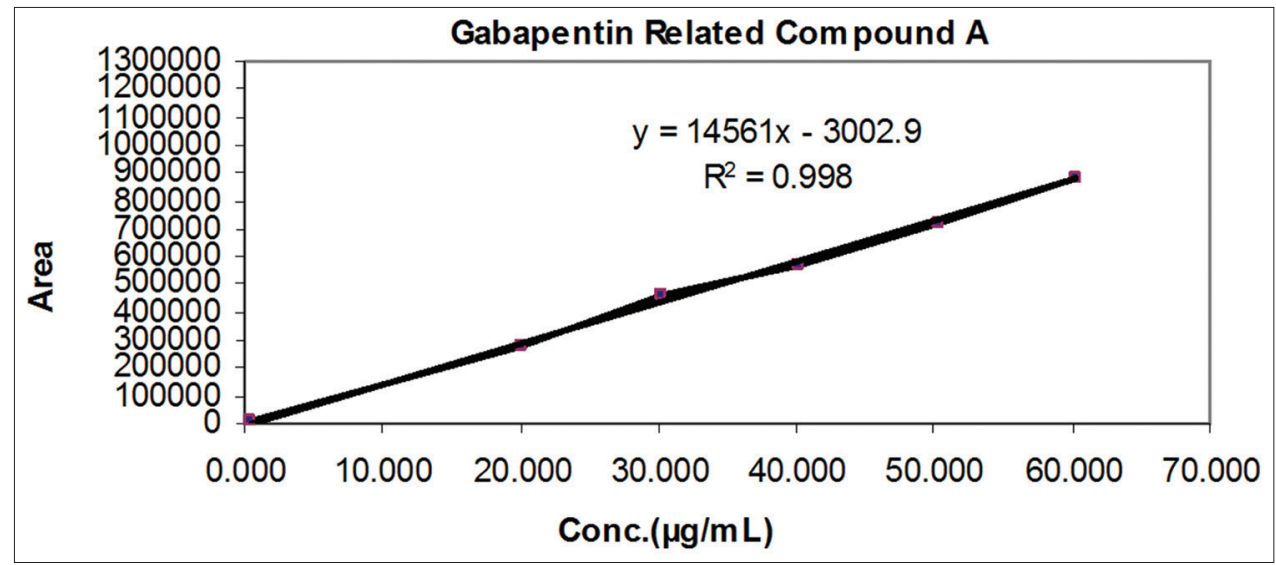

Fig. 4: Linearity graph of gabapentin related compound A

Table 4: Percentage of GBP-related compound A at RT 34.4 for six samples of the same batch

\begin{tabular}{llll}
\hline Sample ID & $\begin{array}{l}\text { Weight of sample } \\
\text { taken }(\mathbf{m g})\end{array}$ & $\begin{array}{l}\text { GBP-related compound A at } \\
\text { RT } \sim 34.4\end{array}$ & $\begin{array}{l}\text { \% of GBP-related compound A at RT 34.4 with respect to } \\
\text { GBP-related compound A (standard solution) }\end{array}$ \\
\hline Sample-1 & 661.53 & 40,925 & 0.01 \\
Sample-2 & 660.85 & 36,944 & 0.01 \\
Sample-3 & 661.36 & 39,602 & 0.01 \\
Sample-4 & 661.40 & 39,902 & 0.01 \\
Sample-5 & 661.62 & 39,154 & 0.01 \\
Sample-6 & 661.92 & 40,986 & 0.01 \\
Mean & & & 0.01 \\
SD & & & 0.00 \\
\% RSD & & & 0.0 \\
\hline
\end{tabular}

GBP: Gabapentin, SD: Standard deviation, RSD: Relative standard deviation

Table 5: Percentage of total impurities for six samples of the same batch

\begin{tabular}{ll}
\hline Sample ID & Total impurities (\%) \\
\hline Sample-1 & 0.01 \\
Sample-2 & 0.01 \\
Sample-3 & 0.01 \\
Sample-4 & 0.01 \\
Sample-5 & 0.01 \\
Sample-6 & 0.01 \\
Mean & 0.01 \\
SD & 0.00 \\
\% RSD & 0.0 \\
\hline
\end{tabular}

Limit of detection (LOD) and LOQ

LOD and LOQ values of related substance and GBP can be predicted based on $\mathrm{S} / \mathrm{N}$ ratio method. For this, the $100 \%$ linearity solutions of each related substance and GBP were considered from the respective linearity experiment. The signal-to-noise ratio should be 10 and 3.3 for LOQ and LOD, respectively. Each anticipated concentration was checked by setting the solutions at about anticipated concentrations and infusion every solution 6 times into the chromatograph independently. Percentage RSD for the areas obtained for the six replicate injections of GBP and each related substance has been given in Tables 9-12.

Specificity/selectivity

This method proves the specificity of the analytical technique for the estimation of related substances in GBP $400 \mathrm{mg}$ capsules by HPLC. 
Table 6: Intermediate precision details

\begin{tabular}{llll}
\hline Experiment name & Method precision & \\
\hline Analyst & Analyst 1 & Analyst 2 \\
Equipment ID & FD-20 & FD-21 & LC005 \\
Column ID & LC004 & \\
Day & November 27, 2010 & \\
\hline Impurity name & Overall impurity summary & \\
\cline { 2 - 3 } & Mean & SD & 2010 \\
\hline GBP-related compound A & 0.01 & 0.00 \\
Any unknown impurity & Not applicable & Not applicable \\
Total impurities & 0.01 & 0.00 & 0.0 \\
\hline
\end{tabular}

GBP: Gabapentin, SD: Standard deviation, RSD: Relative standard deviation

Table 7: Linearity of GBP

\begin{tabular}{lll}
\hline $\begin{array}{l}\text { Percent solution with } \\
\text { respect to specification limit }\end{array}$ & Concentration $(\boldsymbol{\mu g} / \mathbf{m l})$ & Area \\
\hline LOQ & 6.804 & 5534 \\
50 & 20.160 & 15160 \\
75 & 30.240 & 21557 \\
100 & 40.320 & 31977 \\
125 & 50.400 & 39727 \\
150 & 60.480 & 47121 \\
Slope & & 790 \\
Intercept & & -586 \\
Correlation coefficient & & 0.998 \\
$\mathrm{R}^{2}$ & & 0.996 \\
\hline
\end{tabular}

GBP: Gabapentin, LOQ: Limit of quantification

Table 8: Linearity of GBP-related compound A

\begin{tabular}{lll}
\hline $\begin{array}{l}\text { Percent solution with } \\
\text { respect to specification limit }\end{array}$ & Concentration $(\boldsymbol{\mu g} / \mathbf{m l})$ & Area \\
\hline LOQ & 0.503 & 6478 \\
50 & 20.120 & 281,328 \\
75 & 30.180 & 456,939 \\
100 & 40.240 & 566,144 \\
125 & 50.300 & 723,277 \\
150 & 60.360 & 884,844 \\
Slope & & 14,561 \\
Intercept & & -3003 \\
Correlation coefficient & & 0.999 \\
$\mathrm{R}^{2}$ & & 0.998 \\
\hline
\end{tabular}

GBP: Gabapentin, LOQ: Limit of quantification

Table 9: Range

\begin{tabular}{ll}
\hline Impurity name & Range (\% of specification) \\
\hline GBP-relate compound A & OQ to 150 \\
\hline
\end{tabular}

GBP: Gabapentin, LOQ: Limit of quantification

Table 10: LOD and LOQ for GBP

\begin{tabular}{lll}
\hline Injection ID & \multicolumn{2}{c}{ Area of GBP } \\
\cline { 2 - 3 } & LOD & LOQ \\
\hline 1 & 1648 & 6025 \\
2 & 1717 & 5850 \\
3 & 1677 & 5847 \\
4 & 1569 & 5851 \\
5 & 1543 & 6199 \\
6 & 1623 & 5984 \\
Mean & 1630 & 5959 \\
SD & 65.5 & 140.5 \\
$\%$ RSD & 4.0 & 2.4 \\
Con. $(\mu \mathrm{g} / \mathrm{mL})$ & 2.244 & 6.801 \\
\hline
\end{tabular}

LOD: Limit of detection, LOQ: Limit of quantification, GBP: Gabapentin,

SD: Standard deviation, RSD: Relative standard deviation
Table 11: LOD and LOQ for GBP-related compound A

\begin{tabular}{lll}
\hline Injection ID & \multicolumn{2}{l}{ Area of GBP-related compound A } \\
\cline { 2 - 3 } & LOD & LOQ \\
\hline 1 & 1548 & 6789 \\
2 & 1812 & 6989 \\
3 & 1831 & 6812 \\
4 & 1852 & 6748 \\
5 & 1923 & 7136 \\
6 & 1622 & 7193 \\
Mean & 1765 & 6945 \\
SD & 146.0 & 190.1 \\
$\%$ RSD & 8.3 & 2.7 \\
Con. $(\mu \mathrm{g} / \mathrm{mL})$ & 0.166 & 0.503 \\
\hline
\end{tabular}

LOD: Limit of detection, LOQ: Limit of quantification, GBP: Gabapentin, SD: Standard deviation, RSD: Relative standard deviation

Table 12: LOD and LOQ for GBP,GBP-related compound A

\begin{tabular}{llll}
\hline S. No. & Impurity name & LOD $(\boldsymbol{\mu g} / \mathbf{m L})$ & LOQ $(\mu \mathrm{g} / \mathbf{m L})$ \\
\hline 1. & GBP-related compound A & 0.166 & 0.503 \\
2. & GBP & 2.244 & 6.801 \\
\hline LOD: Limit of detection, LOQ: Limit of quantification, GBP: Gabapentin
\end{tabular}

Table 13: Data from spiked sample

\begin{tabular}{|c|c|c|c|}
\hline \multirow[t]{2}{*}{ Name } & \multirow[t]{2}{*}{ RT } & \multicolumn{2}{|l|}{ Peak purity } \\
\hline & & Purity angle & Purity threshold \\
\hline GBP & 6.685 & 0.645 & 0.663 \\
\hline GBP-related compound A & 34.503 & 0.055 & 0.213 \\
\hline
\end{tabular}

GBP: Gabapentin

Table 14: Peak purity of GBP data from control sample

\begin{tabular}{llll}
\hline Sample ID & \multirow{2}{*}{ RT } & \multicolumn{2}{l}{ Peak purity } \\
\cline { 3 - 4 } & & Purity angle & Purity threshold \\
\hline GBP & 6.682 & 0.583 & 0.665 \\
GBP-related compound A & 34.512 & 0.560 & 0.636 \\
\hline GBP: Gabapentin & & &
\end{tabular}

Selectivity of the method has been established by injecting the following:

a. Standard and test solutions, prepared as per test method as a part of identification.

b. Blank and placebo solutions to check any interference of peaks from these solutions with that of the analyte peaks.

c. All the related substances solutions individually to confirm the retention times.

d. Control Sample (capsule sample) and Spiked Sample (Sample spiked with all known related substances at specification level).

e. GBP to confirm the retention time.

The data are represented in Tables 13 and 14. 
Table 15: Stability of GBP-related compound A (standard)

\begin{tabular}{lll}
\hline Sample ID & \multicolumn{2}{l}{ Area of GBP-related compound A } \\
\cline { 2 - 3 } & Area & \% Difference \\
\hline Initial & 651,914 & - \\
After 2 h & 651,434 & 0.1 \\
After 4 h & 650,035 & 0.3 \\
After 6 h & 651,434 & 0.1 \\
After 8 h & 648,785 & 0.5 \\
After 10 h & 648,152 & 0.6 \\
After 12 h & 648,162 & 0.6 \\
After 14 h & 648,386 & 0.5 \\
After 16 h & 646,013 & 0.9 \\
After 18 h & 645,712 & 1.0 \\
After 20 h & 651,501 & 0.1 \\
After 2 h & 648,538 & 0.5 \\
After 24 h & 648,302 & 0.6 \\
\hline
\end{tabular}

GBP: Gabapentin

Table 16: Stability of GBP (standard)

\begin{tabular}{lcc}
\hline Sample ID & \multicolumn{2}{c}{ Area of GBP } \\
\cline { 2 - 3 } & Area & \% Difference \\
\hline Initial & 34,690 & - \\
After 2 h & 35,056 & -1.1 \\
After 4 h & 35,141 & -1.3 \\
After 6 h & 35,069 & -1.1 \\
After 8 h & 35,008 & -0.9 \\
After 10 h & 35,047 & -1.0 \\
After 12 h & 35,164 & -1.4 \\
After 14 h & 35,273 & -1.7 \\
After 16 h & 35,513 & -2.4 \\
After 18 h & 35,187 & -1.4 \\
After 20 h & 35,417 & -2.1 \\
After 22 h & 35,435 & -2.1 \\
After 24 h & 35,433 & -2.1 \\
\hline
\end{tabular}

GBP: Gabapentin

Table 17: Stability of GBP-related compound A (sample)

\begin{tabular}{lll}
\hline Sample ID & \multicolumn{2}{c}{ Area of GBP-related compound A } \\
\cline { 2 - 3 } & Area & \% Difference \\
\hline Initial & 45,116 & - \\
After 2 h & 45,100 & 0.0 \\
After 4 h & 44,934 & 0.4 \\
After 6 h & 45,703 & -1.3 \\
After 8 h & 45,029 & 0.2 \\
After 10 h & 45,645 & -1.2 \\
After 12 h & 45,065 & 0.1 \\
After 14 h & 45,669 & -1.2 \\
After 16 h & 45,944 & -1.8 \\
After 18 h & 46,084 & -2.1 \\
After 20 h & 44,823 & 0.6 \\
After 22 h & 46,532 & -3.1 \\
After 24 h & 46,518 & -3.1 \\
\hline
\end{tabular}

GBP: Gabapentin

\section{Stability of analytical solutions}

Stability of standard and test solutions at room temperature $\left(25^{\circ} \mathrm{C}\right)$ was established by injecting the standard, and test solutions were made according to test technique at various time intervals by keeping all the standard and test solutions at room temperature $\left(\sim 25^{\circ} \mathrm{C}\right)$. GBP area in standard solution was measured, and the difference in the area was calculated. The areas of known and unknown related substances in sample solution were measured, and the percentage differences of areas were calculated. The values for the stability of standard and samples solutions have been presented in Tables 15-18.
Table 18: Stability of GBP (sample)

\begin{tabular}{lll}
\hline Sample ID & \multicolumn{2}{l}{ Area of GBP } \\
\cline { 2 - 3 } & Area & \% Difference \\
\hline Initial & $16,706,661$ & - \\
After 2 h & $16,715,428$ & -0.1 \\
After 4 h & $16,723,944$ & -0.1 \\
After 6 h & $16,718,998$ & -0.1 \\
After 8 h & $16,707,811$ & 0.0 \\
After 10 h & $16,705,271$ & 0.0 \\
After 12 h & $16,716,568$ & -0.1 \\
After 14 h & $16,720,348$ & -0.1 \\
After 16 h & $16,730,682$ & -0.1 \\
After 18 h & $16,792,874$ & -0.5 \\
After 20 h & $16,818,753$ & -0.7 \\
After 22 h & $16,795,617$ & -0.5 \\
After 24 h & $16,728,026$ & -0.1 \\
\hline
\end{tabular}

GBP: Gabapentin

Table 19: Result from standard - system suitability solution

\begin{tabular}{lllll}
\hline Condition & Variation & $\begin{array}{l}\text { USP } \\
\text { Tailing- }\end{array}$ & \multicolumn{2}{l}{ \%RSD } \\
\cline { 4 - 5 } & & GBP & GBP & $\begin{array}{l}\text { GBP-related } \\
\text { compound A }\end{array}$ \\
\hline STP & Actual & 1.1 & 0.4 & 0.4 \\
Flow rate (mL/min) & 1.3 & 1.1 & 0.3 & 0.1 \\
& 1.7 & 1.1 & 0.3 & 0.1 \\
\% organic composition & $720: 280$ & 1.1 & 0.3 & 0.2 \\
(solution: Acetonitrile) & $680: 320$ & 1.1 & 0.3 & 0.1 \\
Column oven & 20 & 1.1 & 0.4 & 0.2 \\
temperature $\left({ }^{\circ} \mathrm{C}\right)$ & 30 & 1.1 & 0.3 & 0.1 \\
Wavelength $(\mathrm{nm})$ & Actual & 1.1 & 0.6 & 0.5 \\
& 208 & 1.1 & 1.2 & 0.3 \\
& 212 & 1.1 & 1.0 & 0.9 \\
\hline
\end{tabular}

GBP: Gabapentin, RSD: Relative standard deviation

Table 20: Result from spiked sample

\begin{tabular}{lll}
\hline Condition & Variation & $\begin{array}{l}\text { GBP-related compound A } \\
\text { retention time }\end{array}$ \\
\hline STP & Actual & 34.747 \\
Flow rate $(\mathrm{mL} / \mathrm{min})$ & 1.3 & 36.690 \\
& 1.7 & 33.067 \\
\% Organic composition & $720: 280$ & 35.989 \\
(solution: Acetonitrile) & $680: 320$ & 33.513 \\
Column oven & 20 & 35.285 \\
temperature $\left({ }^{\circ} \mathrm{C}\right)$ & 30 & 34.509 \\
Wavelength $(\mathrm{nm})$ & Actual & 34.503 \\
& 208 & 34.503 \\
& 210 & 34.503 \\
\hline
\end{tabular}

GBP: Gabapentin

\section{Robustness}

In analytical technique, robustness was established by infusing system suitability solution and sample solution added with other known related substances at particular specification level into HPLC under deliberately modified chromatographic conditions. The results from system suitability and spiked sample were meeting the acceptance criteria at each of the variable condition, and the results have been presented in Tables 19 and 20.

\section{System suitability}

To confirm the suitability of the chromatographic system described under the technique which is analyzed by establishing system suitability parameters such as percentage RSD and tailing factor. Standard was prepared and injected into chromatography as per methodology on a 
Table 21: Result from system suitability on daily basis

\begin{tabular}{|c|c|c|c|c|}
\hline \multirow[t]{2}{*}{ S. No. } & \multirow[t]{2}{*}{ Parameters } & \multirow[t]{2}{*}{ GBP USP tailing factor } & \multicolumn{2}{|c|}{$\%$ RSD } \\
\hline & & & GBP & GBP-related compound A \\
\hline 1 & Repeatability & 1.1 & 0.5 & 0.3 \\
\hline 3 & Robustness & 1.1 & 0.4 & 0.4 \\
\hline 4 & LOD-LOQ prediction & 1.1 & 0.6 & 0.1 \\
\hline 5 & LOD-LOQ precision (GABA) & 1.1 & 0.6 & 0.5 \\
\hline 6 & LOD-LOQ precision (Imp-A) & 1.1 & 0.5 & 0.5 \\
\hline 7 & Accuracy & 1.1 & 0.5 & 0.4 \\
\hline 8 & Ruggedness & 1.0 & 0.7 & 0.9 \\
\hline 9 & Specificity & 1.1 & 0.6 & 0.5 \\
\hline 10 & Linearity & 1.1 & 1.2 & 1.3 \\
\hline
\end{tabular}

GABA: Gamma-aminobutyric acid, GBP: Gabapentin, RSD: Relative standard deviation, LOD-LOQ: Limit of detection-limit of quantification

daily basis. The tailing factor for GBP extent in the standard was not $>2.0$, and the results are shown in Table 21 .

\section{CONCLUSION}

The literature survey indicates that several techniques have been already reported for the estimation of GBP in various dosage forms. However, very little information has been reported for excipient compatibility and related substances of GBP.

The literature survey indicates that when lactose monohydrate, maize starch was used as an excipient for GBP, it produced degradation product called lactam by Maillard-type condensation reaction due to the presence of more water content and hence water activity.

Hence, an effort has been made to find an RP-HPLC technique for studying excipient compatibility and related substances of GBP in capsule dosage form by using excipients such as lactose anhydrous and dried maize starch which is having less water activity.

A RP-HPLC technique is initiated for the estimation of related substances of GBP in the capsule dosage form. Waters Alliance e2695 separation module with $\mathrm{UV} /$ photodiode array (PDA) detector with Inertsil C8 (250 $\mathrm{mm} \times 4.6 \mathrm{~mm}) ; 5 \mu \mathrm{m}$ with an injection volume of $50 \mu \mathrm{l}$ is injected and eluted with the (Gradient program) mobile phase A buffer: acetonitrile (940:60) and mobile phase B buffer: Acetonitrile ACN (700:300) pH 6.9 with $5 \mathrm{~N}$ potassium hydroxide which is pumped at a flow rate of $1.5 \mathrm{~mL} / \mathrm{min}$ and detected by UV/PDA detector at $210 \mathrm{~nm}$. The peaks of GBP and GBP-related compound A are well separated at $6.7 \mathrm{~min}$ and $34.5 \mathrm{~min}$, respectively.

The developed technique is validated for various parameters according to the ICH guidelines such as linearity, accuracy, precision, intermediate precision, specificity, range, robustness, LOD, LOQ, stability, and system suitability. The results got were according to the acceptance criteria.

The proposed technique is assured for detection of related substances in marketed formulation. Hence, the proposed technique observed to be agreeable and could be utilized for the routine analysis of GBP and GBP-related compound A in the capsule dosage form.

\section{ACKNOWLEDGMENT}

I express my heartfelt gratitude to Vels Institute of Sciences, Technology and Advanced Studies, for providing me the research and library facilities for my research work. I also express my sincere thanks to Aurobindo Pharmaceuticals, Hyderabad, for providing me the drugs.

\section{REFERENCES}

1. Cutrignelli A, Denora N, Lopedota A, Trapani A, Laquintana V, Latrofa A, et al. Comparative effects of some hydrophilic excipients on the rate of gabapentin and baclofen lactamization in lyophilized formulations. Int J Pharm 2007;332:98-106.
2. Souri E, Jalalizadeh H, Shafiee A. Optimization of an HPLC method for determination of gabapentin in dosage forms through derivatization with 1-fluoro-2,4-dinitrobenzene. Chem Pharm Bull (Tokyo) 2007; 55:1427-30

3. Ciavarella AB, Gupta A, Sayeed VA, Khan MA, Faustino PJ. Development and application of a validated HPLC method for the determination of gabapentin and its major degradation impurity in drug products. J Pharm Biomed Anal 2007;43:1647-53.

4. Yagi T, Naito T, Mino Y, Takashina Y, Umemura K, Kawakami J, et al. Rapid and validated fluorometric HPLC method for determination of gabapentin in human plasma and urine for clinical application. J Clin Pharm Ther 2012;37:89-94.

5. Amini M, Rouini MR, Asad-Paskeh A, Shafiee A. A new pre-column derivatization method for determination of gabapentin in human serum by HPLC using UV detection. J Chromatogr Sci 2010;48:358-61.

6. Bahrami G, Mohammadi B. Sensitive microanalysis of gabapentin by high-performance liquid chromatography in human serum using precolumn derivatization with 4-chloro-7-nitrobenzofurazan: Application to a bioequivalence study. J Chromatogr B Analyt Technol Biomed Life Sci 2006;837:24-8

7. Cai Y, Yang J, Wang Y, Bai K, Li H. Determination of gabapentin using capillary electrophoresis with laser-induced fluorescence detection. Se $\mathrm{Pu}$ 2010;28:1179-84.

8. Sekar R, Azhaguvel S. Indirect photometric assay determination of gabapentin in bulk drug and capsules by capillary electrophoresis. J Pharm Biomed Anal 2004;36:663-7.

9. Hsu $\mathrm{CH}, \mathrm{Ke}$ WT, Lin SY. Progressive steps of polymorphic transformation of gabapentin polymorphs studied by hot-stage FTIR microspectroscopy. J Pharm Pharm Sci 2010;13:67-77.

10. Siddiqui FA, Arayne MS, Sultana N, Qureshi F, Mirza AZ, Zuberi MH, et al. Spectrophotometric determination of gabapentin in pharmaceutical formulations using ninhydrin and pi-acceptors. Eur $\mathrm{J}$ Med Chem 2010;45:2761-7.

11. Abdellatef HE, Khalil HM. Colorimetric determination of gabapentin in pharmaceutical formulation. J Pharm Biomed Anal 2003;31:209-14.

12. Belal F, Abdine H, Al-Majed A, Khalil NY. Spectrofluorimetric determination of vigabatrin and gabapentin in urine and dosage forms through derivatization with fluorescamine. J Pharm Biomed Anal 2002;27:253-60

13. Hassan EM, Belal F, Al-Deeb OA, Khalil NY. Spectrofluorimetric determination of vigabatrin and gabapentin in dosage forms and spiked plasma samples through derivatization with 4-chloro-7-nitrobenzo-2oxa-1,3-diazole. J AOAC Int 2001;84:1017-24.

14. Al-Zehouri J, Al-Madi S, Belal F. Determination of the antiepileptics vigabatrin and gabapentin in dosage forms and biological fluids using hantzsch reaction. Arzneimittelforschung 2001;51:97-103

15. Gupta A, Ciavarella AB, Sayeed VA, Khan MA, Faustino PJ. Development and application of a validated HPLC method for the analysis of dissolution samples of gabapentin drug products. J Pharm Biomed Anal 2008;46:181-6.

16. Lakshmi B. RP-HPLC method development for the quantification of gabapentin in formulations. Exp 2012;2:84-92.

17. Gujral RS, Haque SM. Development and validation of a new HPLC method for the determination of gabapentin. Int J Biomed Sci 2009;5:63-9.

18. Das B. Estimation of gabapentin in human plasma using Lc-Ms/Ms method. Asian J Clin Pharm Res 2013;6:213-6.

19. Hymavathi K, Babu DM, Patan A. Development and validation of 
RP-HPLC method for the estimtion of tenofovir disproxil fumarate and lamiudine in combined dosage form. Int J Appl Pharm Biomed Sci 2012;2:144-8.

20. Devi VA. RP-HPLC method for quantitative estimation of glatiramer acette for injection in pharmaceutical dosage forms. Experiment
2012;3:193-8

21. Kumari MV, Devi VA, Nareshbabu AV, Patan A, Anjaneyulu V. New stability indicting RP-HPLC method for estimation of mycophenolate mofetil capsule in pharmaceutical dosage form. Int Res J Pharm Appl Sci 2012;2:149-54 